\title{
Partner notification for HIV infection in the United Kingdom: A look back on seven years experience in Newcastle upon Tyne
}

\author{
Richard S Pattman, Elspeth M Gould
}

\begin{abstract}
Objective-To examine the outcome of partner notification for HIV infection. Design-Retrospective analysis of medical, health adviser and counsellor records.

Setting-Teaching hospital, Newcastle upon Tyne.

Patients-All newly diagnosed cases of human immunodeficiency virus (HIV) infection and their sexual partners.

Main outcome measures-Attendance of contact at genitourinary medicine clinics for counselling and testing. Seropositivity rate of people attending as a result of partner notification.

Results-Of the 80 partners attending as a result of partner notification 79 were tested. Twenty-five of these $(31 \cdot 6 \%)$ were seropositive. This was $21.9 \%$ of our newly diagnosed caseload. Seventy-five attended following patient referral and five as a result of provider referral. Discrepancies between districts in policies of provider referral prevented two partners being notified.

Conclusions-Partner notification is an effective method of ensuring that people with a very high risk of HIV infection have access to counselling and medical care. Complete integration of notification services throughout the UK is required.
\end{abstract}

(Genitourin Med 1993;69:94-97)

\section{Introduction}

Contact tracing to combat the spread of sexually transmitted diseases (STDs) was instituted in 1937 by the US Surgeon General. ${ }^{1}$ In 1943 it was developed in the UK when the Medical Officer of Health for Newcastle upon Tyne, Dr John Charles, inaugurated the "Tyneside Scheme" to include the County Councils of Durham and Northumberland and the County Borough Councils of Gateshead, Newcastle upon Tyne, Tynemouth and South Shields. ${ }^{2}$ The "Scheme" was a local authority initiative which included an education programme for all interested in fighting venereal disease, the routine serological testing of antenatal cases for syphilis as well as the inauguration of contact tracing. There is therefore a long tradition of contact tracing in Newcastle.

The terminology has altered over the years and now in the USA "contact tracing" equates with "provider referral" in which named partners of infected individuals are located and counselled by health care staff. ${ }^{3}$ The term "partner notification" has been advocated by the World Health Organisation and the Centers for Disease Control ${ }^{45}$ to include both "provider referral" and "patient referral" in which patients or "index cases" notify their partners themselves, often coached and advised by health care staff. This covers the spectrum of activities in which sexual and needle-sharing partners of persons with HIV infection are notified and counselled about their exposure. Throughout this paper we shall use the terms partner notification, provider referral and patient referral as defined above.

The value of partner notification for the control of sexually transmitted infections is well recognized. ${ }^{6}$ It can reduce the number of cases of gonorrhoea and syphilis as compared with the numbers anticipated and has helped to control outbreaks of these diseases. ${ }^{78}$

Even in genital chlamydial infection with a longer and more uncertain incubation period the benefit of detecting asymptomatic carriage of Chlamydia trachomatis has been clearly demonstrated. ${ }^{9}$

As part of the management of human immunodeficiency virus (HIV) infection Sweden, Norway, Belgium and most states in the USA $^{10}$ have implemented programmes emphasising partner notification. Their results have been widely reported. ${ }^{311-14}$ An official policy has not been developed within the UK and we have found no documented information on its effectiveness from centres operating this strategy. Since the onset of the HIV epidemic we, in Newcastle, have continually promoted partner notification, largely based on patient referral, and present a retrospective analysis of our data.

\section{Subjects and methods}

Genitourinary medicine (GUM) provides an open access educational, preventative, diagnostic and therapeutic service in relation to sexually transmissible infections and certain other conditions affecting the genital organs. The majority of service users $(55 \%)$ self refer. $16 \%$ attend as a result of partner notification and the remainder are referred by other clinicians, usually general practitioners. The department, based in Newcastle upon Tyne is mainly used by the residents of Newcastle, Northumberland and Gateshead (total population 787,000 ). However about $20 \%$ of the Newcastle caseload is comprised of patients 
residing in other Districts with local GUM services who travel to Newcastle.

The promotion, coordination and facilitation of partner notification for STDs is part of the role of the health advisers, which also encompasses pre and post HIV test counselling, health education within and outside of the clinic, referral on to other appropriate agencies and staff training.

In the UK there is no specific health adviser training available. Health visitors have been involved with partner notification in Newcastle and its surrounding districts since the inception of the "Tyneside Scheme". They are registered general nurses who have undertaken further training which includes epidemiology sociology, social policy, psychology and health promotion. Registered Health Visitors in GUM have had experience working in primary health care promoting individual, family and public health, - and adapt their skills in these areas to the specialist area of the GUM clinic. During the study period, the number of health adviser posts increased incrementally from one to four whole time equivalents. For a period of 19 months in 1987-1988 an AIDS Counsellor worked alongside the health advisers.

As with any STD, health advisers discuss index patients' sexual histories with them in order to decide which partners should be notified and how best this would be achieved. Patients with partners living in distant parts of the UK are given details of GUM clinics to which they can turn for support and testing after they have been informed of their exposure to infection. For provider referral, information is required to locate and identify the person to be sought. Details of contacts' domestic and employment circumstances are also helpful. Using methods, including safeguards to confidentiality, similar to those outline in the "Handbook on Contact Tracing in Sexually Transmitted Diseases" 15 the health advisers then approach the partner by telephone, letter or personal visit. To notify a partner living outside Newcastle we may ask for assistance from a GUM clinic closer to the partner's residence.

In order to review the effect of partner notification since the first cases of HIV infection were detected in 1985 we have analysed information extracted from case records (as described by Satin) ${ }^{16}$ from all seropositive people and seronegative contacts.

\section{Results}

From 1985 to June 1992 this department was directly involved in the management of 114 people with newly diagnosed HIV infection (see table). Ninety-four were diagnosed here and 20 referred shortly after a positive result was obtained by a general practitioner, other local hospital specialist and, in two cases, by the Blood Transfusion Service.

Of the 114 newly diagnosed cases, 93 were homosexual or bisexual men $(81 \cdot 6 \%)$. There was no history of injecting drug use in this cohort. Three heterosexual men probably acquired infection by needle sharing, ten following heterosexual intercourse in SubSaharan Africa and one following heterosexual intercourse in the UK. Seven women were seen with HIV infection. Three were non-injecting sexual partners of male injecting drug users, one the partner of a bisexual man, one probably acquired infection following heterosexual intercourse in Sub-Saharan Africa and the only risk for the remaining two was heterosexual intercourse within the UK. No cases were seen here resulting from the use of infected blood or blood products.

General concern about the possibility of HIV infection in relation to a previous life style risk was given as a reason for testing by 68 people found to be seropositive. All were asymptomatic and include six homosexual men whose concerns were heightened by receiving news that an unspecified partner had HIV infection. Seventeen cases requested testing because of symptoms or signs compatible with HIV infection. Five had probably acquired infection following intercourse in Sub-Saharan Africa and one (a female case) from a bisexual man. Thus only $64.7 \%$ of the sub-group were male homosexuals or bisexuals. Four homosexual men attended as a result of contact with another sexually transmitted disease and following counselling requested HIV testing.

Finally, 25 people were tested and found to be seropositive only as a result of partner notification instituted within this department, although two delayed their initial visit and test until they developed malaise, tiredness, weight loss and night sweats. Twenty-one $(84 \%)$ were homosexual/bisexual men, one was a male heterosexual injecting drug user, one a man who had heterosexual intercourse in Sub-Saharan Africa and the remaining two were heterosexual women. No needle sharing

Table Total new cases of HIV infection seen within GUM and the results of partner notification. 1985-fune 1992

\begin{tabular}{|c|c|c|c|c|c|}
\hline & \multirow[b]{2}{*}{$\begin{array}{l}\text { Total new } \\
\text { HIV infection }\end{array}$} & \multirow[b]{2}{*}{$\begin{array}{l}\text { HIV infection detected } \\
\text { following partner notification }\end{array}$} & \multicolumn{2}{|l|}{$\begin{array}{l}\text { Anti HIV negative } \\
\text { following partner } \\
\text { notification }\end{array}$} & \multirow{2}{*}{$\begin{array}{l}\text { Declined anti-HIV test } \\
\text { following partner } \\
\text { notification and counselling }\end{array}$} \\
\hline & & & $\begin{array}{l}>6 \text { months from } \\
\text { last risk }\end{array}$ & $\begin{array}{l}<6 \text { months from } \\
\text { last risk }\end{array}$ & \\
\hline $\begin{array}{l}\text { Heterosexual } \\
\text { men }\end{array}$ & 14 & 2 & 0 & 0 & 1 \\
\hline $\begin{array}{l}\text { Homosexual } \\
\text { men }\end{array}$ & 93 & 21 & 21 & 23 & 0 \\
\hline Women & 7 & 2 & 7 & 3 & 0 \\
\hline Total & 114 & 25 & 28 & 26 & 1 \\
\hline
\end{tabular}


contacts have been identified. Therefore partner notification has accounted for $21.9 \%$ of newly diagnosed HIV infection.

Partner notification resulted in an additional 55 named contacts attending. Following counselling 54 requested HIV antibody testing and were seronegative. Of these, 28 $(51.9 \%)$ were tested six months after last unprotected intercourse with the index case, seven between three and six months, but 19 were only tested within three months of their last known infection risk despite advice for more prolonged surveillance. One man is still under observation. Only one contact, a heterosexual man concerned about the implication of testing in relation to life insurance and house purchase declined the offer of a test.

Seven positive men named eight male and one female contacts whom they planned to notify themselves (patient referral). From our understanding these partners have been informed of their risk and have decided not to attend for counselling and/or testing. An unrecorded number of patients chose not to inform their partners or had insufficient information to allow them to be located, especially those who had intercourse with several anonymous partners. No accurate figure can be put on these untraceable contacts. No details were recorded for partners resident outside of the UK.

Provider referral was considered appropriate to notify four men and three women named by six seropositive index cases. Three local contacts were requested by letter to telephone for information and one was visited and accepted the offer of transport to the clinic. Of these, three were subsequently tested for STDs including HIV antibodies. The other agreed to attend but has failed to appear. Three index cases named three contacts living distant from Newcastle so the assistance of their local clinics was sought. A clinic in the North West of England declined to help as their policy was not to trace contacts of HIV infection. Personnel from a Midlands clinic agreed to try to locate a male contact but have not informed us on the outcome of their efforts. After her local clinic had declined to contact her a female partner living in South-East England responded to our letter asking her to telephone us and expressed longstanding fears regarding HIV infection. She subsequently attended her local clinic for testing. All of those tested following provider referral were seronegative and expressed appreciation of the action taken on their behalf.

\section{Discussion}

Partner notification followed by counselling and testing has identified 25 new seropositive cases from the 79 people attending on this basis (excluding the man who declined testing). This figure of $31.6 \%$ compares favourably with studies from other countries with emphasis on provider referral. In Sweden ${ }^{11} 15 \%$ of contacts with previously unknown infection were found to be seroposi- tive. A Norwegian study has shown a $13 \%$ seropositivity rate ${ }^{17}$. Reports from the USA indicate that the seroprevalence rate arising from partner notification varies from $7-42 \%{ }^{10}{ }^{14}$ where most states require seropositive people to be reported to the Department of Health.

Our figures for the percentage of partners who have been informed of their risk and of the numbers who subsequently attended for counselling and testing include only those people for whom we have hard evidence. More may have attended without disclosing their identities or that their partners had asked them to attend. There may be others who plan to attend but have yet to find the time and courage to do so. Should they develop symptoms in the meantime they will have knowledge which may lead to an accurate, early diagnosis of their illness.

Our figure of $31.6 \%$ demonstrates the success of operating a voluntary, confidential notification system. New index cases are given as much time, advice and support to initiate patient referral or supply information for provider referral as is required. The basic principles are (a) not to disclose the source of infection and (b) not to disclose the name of the infection unless exceptionally a relevant screening test offered is declined by the contact. These principles are brought to the attention of the index case before further action is taken. This system has operated successfully in the UK for years for other STDs and has been extended to include HIV infection

Keenleyside et al ${ }^{18}$ have recently reported a wide variation in attitudes amongst professional staff working in GUM clinics in the UK. Only $44 \%$ of physicians and $29 \%$ of health advisers in the Thames regions would offer provider referral for HIV infection compared with almost two thirds in both groups elsewhere.

Partner notification for other sexually transmitted diseases resulted in the diagnosis of HIV infection in an additional four patients, all homosexual men who following counselling requested HIV antibody testing. Given that people with HIV infection may have other STDs which require partner notification and given that both patient and provider referral for STDs have identified people who were found to have HIV it is difficult to see a firm dividing line between HIV and other STDs as far as the management of partners is concerned. As the health advisers in Newcastle are all actively involved in partner notification for any STD as well as pre and post test counselling no extra skills are needed although additional resources may be required in the future.

We have not been aware of any misgivings from our patients regarding partner notification as has also been shown in the USA ${ }^{19}$. Although the number of people tested fell from a peak of 1698 in 1987 to 576 in 1989 there has been a steady increase to 1484 in 1991 and 880 for the first half of 1992 . Our policy of partner notification has been consis- 
tent but the demand for testing has apparently increased as the potential benefits of being aware of one's serostatus take precedence over the perceived threats of the test.

To achieve acceptability partner notification should demonstrate benefit. Although the optimum time for introducing antiretroviral treatment and prophylaxis for opportunistic infections has not been established it has been shown that pre-symptomatic intervention decreases morbidity and mortality. ${ }^{20-23}$

The behavioural benefits are less clear cut and vary with the cohort studied. ${ }^{24-28}$ The main advantage may well be to exclude infection in the regular partners of those who are seropositive so that information can be given on risk reduction. However, the increase in gonorrhoea in the UK among homosexual and bisexual men first reported in $1991^{29}$ suggests that advice given is being. ignored, forgotten or that a new population of sexually active young men are appearing who do not relate the safer sex message to themselves.

As HIV infection becomes more distanced from homosexual men and drug users following first ${ }^{30}$ and second ${ }^{31}$ generation transmission, partner notification may become more apposite and cost-effective. This has been documented by Clumeck et al ${ }^{12}$ who reported a cluster of 19 women, 11 of whom were found to be HIV seropositive following sexual intercourse with a single index case. The stage of infection is also important. ${ }^{32}$ We have found partner notification to be of particular value in those who did not perceive themselves to be at a risk of HIV infection from their sexual lifestyle or drug abuse. Of the 80 people who attended following partner notification $18(22.5 \%)$ had not perceived themselves as being at high risk. Five of these were seropositive.

Partner notification should not be seen as anything other than one part of a comprehensive HIV management strategy. It is unlikely to be true for HIV, as it is for bacterial STDs, that early treatment will reduce the lifetime costs of health care for the individual who is found to be HIV positive. Any savings would come from primary prevention efforts with the partners found to be free of infection. However, once the value of partner notification is accepted then provider referral must logically be offered as a service to those people with HIV infection who are unable or unwilling to do the task themselves. In our opinion a unified national policy is required to eliminate geographical discrepancies.

We acknowledge the contribution made to this study by $A M$ Barker, RJ Brown, CA Burrows, MR Das, EM Gunthorpe, MJ MacDermott, Dr KN Sankar, Dr CBS Schofield and D PG Watson.

1 Ramstedt K, Hallhagen G, Lundin B-I et al. Contact tracing for human immunodeficiency virus (HIV) infection. Sex Transm Dis 1990;17:37-41.

2 Wigfield AS. 27 years of uninterrupted contact tracing: the 'Tyneside Scheme' $B r f$ Venereal Dis 1972;48: $37-50$

3 Landis SE, Schoenbach VJ, Weber DJ, et al. Results of a randomized trial of partner notification in cases of HIV infection in North Carolina. N. Engl f Med 1992; 326:101-6.

4 Centers for Disease Control. Partner notification for preventing human immunodeficiency virus (HIV) infection-Colorado, Idaho, South Carolina, Virginia. MMWR 1988;37:393-402.

5 World Health Organization. Prevention of sexual transmission of human immunodeficiency virus. Geneva: World Health Organisation, 1990

6 Adler M W. Contact tracing. BMf 1982;284:1211.

7 Henderson RH. Control of sexually transmitted disease in the United States-a federal perspective. Br $\mathcal{F}$ Venereal Dis 1977;53:211-5.

8 Faruki H, Kohmescher R, McKinney WP, Sparling PF. A community based outbreak of infection with penicillinresistant Neisseria gonorrhoeae not producing pencillinase (chromosomally mediated resistance). N Engl $f \mathrm{Med}$ 1985;313:607-11.

9 Ripa T. Epidemiologic control of genital Chlamydia trachomatis infections. Scand F Infect Dis 1990;Suppl. 69; 157-67.

10 Toomey KE, Cates W. Partner notification for the prevention of HIV infection. AIDS 1989;3 (Suppl 1), S57-S62.

11 Giesecke J, Ramstedt K, Granath F, Ripa T, Rådö G, Westrell M. Efficacy of partner notification for HIV infection. Lancet 1991;338:1096-110.

12 Clumeck N, Taelman H, Hermans P, Piot R, Schoumacher RN, De Wit $S$. A cluster of HIV infection among heterosexual people without apparent risk factors. N Engl f Med 1989;321:1460-2.

13 Wykoff RF, Heath CW, Hollis SL, et al. Contact tracing to identify human immunodeficiency virus infection in a rural community. $\mathcal{F} A M A 1988,259: 3563-6$.

14 Rutherford GW, Woo JM, Neal DP, et al. Partner notification and the control of human immunodeficiency virus infection. Two years of experience in San virus infection. Two years of experience

15 Hunter I, Jacobs J, Kinnell H, Satin A. A Handbook on Contact Tracing in Sexually Transmitted Diseases. I ondon:Health Education Council. 1980.

16 Satin A. A record system for contact tracing. $\mathrm{Br} \mathcal{F}$ Venereal Dis 1977;53:84-7.

17 Kristoffersen JE, Petersen G. Telling one's partner about HIV infection. (In Norwegian). Tidsskr Nor Loegeforen 1991;111:432-3.

18 Keenleyside RA, Hawkins AS, Johnson AM, Adler MW. Attitudes to tracing and notifying contacts of people with HIV infection. BMF 1992;305:165-8.

19 Jones JL, Wykoff RF, Hollis SL, Longshore ST, Gamble WB, Gunn RA. Partner acceptance of health department notification of HIV exposure, South Carolina ment notification of HIV

20 Volberding PA, Lagakos SW, Koch MA, et al. Zidovudine in asymptomatic human immunodeficiency virus infection: a controlled trial in persons with fewer than 500 CD4 - positive cells per cubic millimeter. $N$ Engl f Med 1990;322:941-9.

21 Graham NMH, Zegar SL, Park LP, et al. The effects on survival of early treatment of human immunodeficiency virus infection. N Engl f Med 1992;326:1037-42.

22 Gazzard BG. When should asymptomatic patients with HIV infection be treated with zidovudine? $B M \mathcal{F} 1992$; 304:456-7.

23 Graham NMH, Zegar SL, Park LP, et al. Effect of zidovudine and Pneumocystis carinii pneumonia prophylaxis on progression

24 Higgins DL, Galavotti C, O'Reilly KR, et al. Evidence for the effects of HIV antibody counselling and testing on risk behaviours. $\mathcal{F A M A}$ 1991;266:2419-29.

25 Allen S, Tice J, Van de Perre P, et al. Effect of serotesting with counselling on condom use and seroconversion among HIV discordant couples in Africa. BMF 1992 304:1605-9.

26 Zenilman JM, Erickson B, Fox R, Reichart CA, Hook EW. Effect of HIV post test counselling on STD incidence. $¥ A M A$ 1992;267:843-5.

27 Wilkins HA, Alonso P, Baldeh S, et al. Knowledge of AIDS, use of condoms and results of counselling subjects with asymptomatic HIV 2 infection in The Gambia. AIDS Care 1989;1:247-56.

28 Hassig SE, Kinkela N, Nsa W, et al. Prevention of perinatal HIV transmission: are there alternatives to pre-pregnancy serological screening in Kinshasa, Zaire? AIDS 1990;4:913-6.

29 Riley VC. Resurgent gonorrhoea in homosexual men Lancet 1991;337:183.

30 Evans BG, Noone A, Mortimer JY, et al. Heterosexually acquired HIV-1 infection: cases reported in England, Wales and Northern Ireland 1985 to 1991 . Communicable Disease Report 1992;2:R49-55.

31 Gilbart VL, Evans BG, Noone A, Mortimer JY, Gill ON infection. Communicable Disease Report 1992;2:R55-9.

32 Giesecke J, Ramstedt K, Granath F, Ripa T, Rådö G Westrell $M$. Partner notification as a tool for research in Westrell $M$. Partner notification as a tool for research in
HIV epidemiology: behaviour change, transmission risk and incidence trends. AIDS 1992;6:101-7. 